\title{
Statistical study on the occurrence of ASAID electric fields
}

\author{
S. Liléo, T. Karlsson, and G. T. Marklund \\ Space and Plasma Physics, School of Electrical Engineering, Royal Institute of Technology (KTH), Stockholm, Sweden \\ Received: 21 April 2009 - Revised: 28 October 2009 - Accepted: 26 January 2010 - Published: 8 February 2010
}

\begin{abstract}
The first statistical results on the occurrence of abnormal subauroral ion drifts (ASAID) are presented based on electric and magnetic field measurements from the lowaltitude Astrid-2 satellite. ASAID are narrow regions of rapid eastward ion drifts observed in the subauroral ionosphere. They correspond to equatorward-directed electric fields with peak amplitudes seen to vary between $45 \mathrm{mV} / \mathrm{m}$ and $185 \mathrm{mV} / \mathrm{m}$, and with latitudinal extensions between $0.2^{\circ}$ and $1.2^{\circ}$ Corrected Geomagnetic Latitude (CGLat), reaching in some cases up to $3.0^{\circ}$ CGLat.

Opposite to subauroral ion drifts (SAID) that are known to be substorm-related, ASAID are seen to occur predominantly during extended periods of low substorm activity. Our results show that ASAID are located in the vicinity of the equatorward edge of the auroral oval, mainly in the postmidnight sector between 23:00 and 03:00 magnetic local time. They are associated with a local current system with the same scale-size as the corresponding ASAID, composed by a region of downward field-aligned currents (FACs) flowing in the ASAID poleward side, and a region of upward flowing FACs in the equatorward side. The FACs have densities between 0.5 and $2.0 \mu \mathrm{A} / \mathrm{m}^{2}$. The data suggest that ASAID do not contribute significantly to the reduction of the ionospheric conductivity. ASAID are seen to have life times of at least $3.5 \mathrm{~h}$.

A discussion on possible mechanisms for the generation of ASAID is presented. We speculate that the proximity of the electron to the ion plasma sheet inner boundaries and of the plasmapause to the ring current outer edge, during extended quiet times, is an important key for the understanding of the generation of ASAID electric fields.
\end{abstract}

Keywords. Ionosphere (Electric fields and currents; Ionosphere-magnetosphere interactions; Mid-latitude ionosphere)

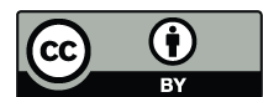

Correspondence to: S. Liléo (sonia.lileo@comhem.se)

\section{Introduction}

Observations of narrow layers of rapid westward ion flow at subauroral latitudes were reported by the first time on 1973 by Galperin et al. (1974). Since then many studies have been conducted on the properties of these features. They have been named PJ (polarization jets) (Galperin et al., 1974), SAID (subauroral ion drifts) (Spiro et al., 1974) or alternatively SAEF (subauroral electric fields) (Karlsson et al., 1998), since they may also be identified as intense poleward electric fields confined to latitudinally narrow regions. SAID are usually defined as regions $0.1^{\circ}-2^{\circ}$ CGLat (Corrected Geomagnetic Latitude) broad with a drift velocity greater than $1000 \mathrm{~m} / \mathrm{s}$, or correspondingly with a poleward-directed electric field with a peak intensity greater than $30 \mathrm{mV} / \mathrm{m}$. Results reported in several studies (e.g. Smiddy et al., 1977; Anderson et al., 1993; Karlsson et al., 1998; Figueiredo et al., 2004; Puhl-Quinn et al., 2007, and references therein) show that the SAID drift peak velocity may reach up to $10 \mathrm{~km} / \mathrm{s}$ (corresponding to an electric field peak amplitude up to $\sim 300 \mathrm{mV} / \mathrm{m}$ ), that they occur predominantly in the 18:0002:00 magnetic local time (MLT) sector with a maximum probability between 20:00 to 23:00 MLT, and are often located equatorward of the auroral oval and poleward of or in the vicinity of the ionospheric projection of the plasmapause $\left(\sim 50^{\circ}-70^{\circ}\right.$ CGLat). They are often detected during the recovery phase of a substorm, and are seen to be more intense and move toward lower latitudes with increasing magnetic activity. SAID are often associated with ionospheric density troughs and with regions of downward FACs with magnitudes between $0.1 \mu \mathrm{A} / \mathrm{m}^{2}$ and $4 \mu \mathrm{A} / \mathrm{m}^{2}$. The life time of SAID varies between $30 \mathrm{~min}$ to $3 \mathrm{~h}$.

Observations on a new type of subauroral phenomena has been reported recently by Voiculescu and Roth (2008). It consists of regions of enhanced eastward ion drifts at subauroral latitudes named by the authors as Abnormal SubAuroral Ion Drifts, ASAID. Strong eastward ion drifts were measured on board the DMSP (Defense Meteorological

Published by Copernicus Publications on behalf of the European Geosciences Union. 
Satellite Program) F15 satellite at about $840 \mathrm{~km}$ altitude, showing local speeds larger than $1 \mathrm{~km} / \mathrm{s}$ and local widths of $1^{\circ}-2^{\circ}$. Two ASAID events observed in the 20:00-21.5 MLT interval were presented. Both cases were accompanied by upward flows of ions with a speed of the same order as the zonal ion drift and coincided with deep narrow troughs in the total ion density at DMSP altitudes $(850 \mathrm{~km})$ and in the F-region of the ionosphere. However the cause-effect relationship between the ASAID and the F-region trough was not possible to establish. The ASAID events were associated with significant increases of the electron temperature while the ion temperature showed no significant variation. Both cases occurred during weak substorm activity and were associated with regions of very weak downward field-aligned currents. The ion zonal velocity was seen to reverse after a period of $9-12 \mathrm{~h}$, turning the events into classical SAID events.

The analysis of the location of the ASAIDs relative to the precipitation regions showed that both events were observed slightly equatorward of the ionospheric mapping of the plasmapause, suggesting that they were magnetically connected to a generator located very close to the plasmapause. Voiculescu and Roth (2008) proposed that intense radial electric fields directed inward (toward magnetic shells with lower L-values) may occur when the outer edge of the ring current coincides with the plasmapause due to finite gyroradius effects at this interface: the larger Larmor radius of the hot ring current ions creates an excess positive charge in the cold plasmaspheric trough and leaves a deficit of negative charges inside the ring current region. The resultant electric field points radially inward and maps down to the ionosphere as a subauroral equatorward-directed electric field, associated with eastward ion drift flow. The ASAID/SAID turning was suggested to occur when energetic electrons from the plasma sheet came close enough to the ion sheet associated with the ASAID, to generate an electric field pointing radially outward close to the plasmapause, that maps to the ionosphere as a poleward-directed electric field.

Eastward subauroral ion drifts have also been reported by Ebihara et al. (2008) based on two-dimensional measurements of ionospheric plasma flows made by the midlatitude SuperDARN Hokkaido radar. Two eastward flow events observed in the predusk region (between 14.5 and 16:00 MLT) associated with an intense magnetic storm were reported. These events were however associated with relatively slower drift velocities $(\sim 50-70 \mathrm{~m} / \mathrm{s})$ and with broader widths $\left(\sim 3^{\circ}\right)$, as compared to the observations by Voiculescu and Roth (2008). The first event occurred immediately after a northward turning of the IMF that pointed southward for about $6 \mathrm{~h}$ during the main phase of a storm. The authors suggest that the dawn-to-dusk convection electric field may be overshielded by an opposite directed and more intense electric field (shielding electric field) associated with the closure of the region-2 FACs. The plasma flow in the dusk sector would then be antisunward at subauroral latitudes. Overshielding is expected to occur when the IMF suddenly turns northward after a prolonged southward orientation, because the magnitude of the pressure gradients that generate the region-2 FACs in the inner magnetosphere takes longer time to decrease, as a response to the northward IMF turning, than the convection electric field. Particle data from the DMSP F13 satellite that crossed the field of view of the Hokkaido radar during this event showed that the eastward plasma flow occurred equatorward of the ionospheric mapping of the inner edge of the plasma sheet electron precipitation between $54^{\circ}$ and $58^{\circ}$ magnetic latitude.

The second event was observed one hour later at slightly lower magnetic latitudes. The IMF remained southward during this event. The authors propose that the shielding electric field may however still overcome the convection electric field in this case if a shrinkage of the polar cap happens without a decrease in the cross-polar cap potential drop, or if an enhancement of the shielding electric field occurs due to a sudden strengthening of the inertial current converted from an abrupt field-aligned injection of magnetospheric hot ions from the nightside plasma sheet. However neither explanation was shown to fully account for the observations.

\section{Observations}

The Astrid-2 satellite was a Swedish micro-satellite launched on 10 December 1998. It was placed in a circular orbit at $1000 \mathrm{~km}$ altitude with $83^{\circ}$ inclination and an orbital period of $105 \mathrm{~min}$. It remained operational until July 1999. The orbital plane regressed $180^{\circ}$ relative to the Sun in approximately 4 months, allowing the coverage of all local times during the life time of the spacecraft.

Electric field and magnetic field data measured at a rate of 16 samples per second by the EMMA (Electric and Magnetic Monitoring of the Aurora) instrument are used in this study. The EMMA instrument provides simultaneous sampling of the two spin plane components of the electric field and of the full magnetic field vector. The electric field component along the spin axis is not measured but can be reconstructed using the assumption $\boldsymbol{E} \times \boldsymbol{B}=0$. This is a reasonable assumption considering that field-aligned electric fields are not expected to occur at the spacecraft altitude. Detailed descriptions of the Astrid-2 satellite and of the EMMA instrument are given by Marklund et al. (2001) and Blomberg et al. (2004), respectively.

This statistical study is based on data from approximately 2900 crossings of the Northern and Southern auroral ovals between January and July 1999. A fairly good orbital coverage of all local times was provided by these data as shown in Fig. 1.

Figure 2 shows an example of an ASAID event measured on 9 April 1999. The electric and magnetic field data were projected into the MEE (Magnetic field-aligned Eastward Equatorward) coordinate system where $\boldsymbol{e}_{1 \text { mee }}$ is the magnetic 

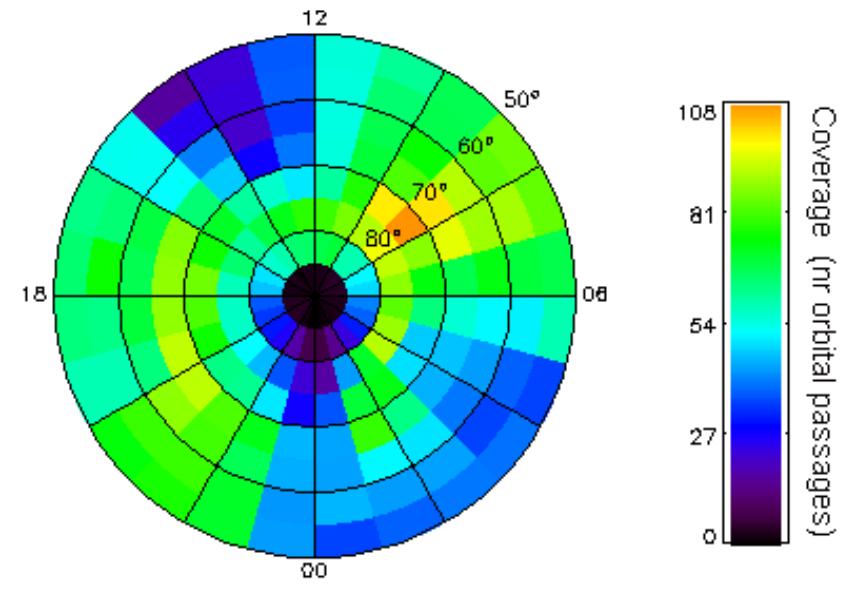

Fig. 1. Orbital coverage corresponding to the data set used in this study.

field-aligned direction, $\boldsymbol{e}_{2 \text { mee }}$ points to the magnetic east and $\boldsymbol{e}_{3 \text { mee }}$ equatorward. The magnetic field orientation is derived from the International Geomagnetic Reference Field (IGRF) model that represents the main geomagnetic field without external sources, giving a good approximation for the geomagnetic field traversed by low-altitude satellites. The eastward and equatorward components of the electric field are plotted in the two first panels of Fig. 2. The two last panels show the eastward and the equatorward components of the magnetic field. Universal time, altitude in kilometers, CGLat and MLT are shown on the horizontal axis. At about 23:34 UT, the electric field is mainly equatorward-directed and reaches a peak amplitude of $\sim 115 \mathrm{mV} / \mathrm{m}$. The variations of the eastward component of the magnetic field correspond to a system of FACs flowing downward in the poleward side of the electric field structure and upward in the equatorward side. The direction of the ionospheric closure current is therefore equatorward, coincident with the direction of the observed electric field. The small amplitude oscillations seen in both the eastward and the equatorward components of the magnetic field are the result of imprecisions in the determination of the spacecraft's attitude, probably associated with fluctuations of the angle between the satellite spin axis and the extended boom where the EMMA's magnetometer is located.

A polar plot in geomagnetic coordinates of the estimated location of the Northern auroral oval at 23:34 UT on 9 April 1999 is also shown in Fig. 2. This plot was obtained using the OVATION tool available through the website of the John Hopkins University Applied Physics Laboratory (JHU/APL). OVATION estimates the position of the auroral oval boundaries by using multiple data sets crosscalibrated to a single standard. The data sources used are the DMSP satellites, the Polar UVI imager and the Fairbanks Meridian Scanning Photometer from the University of Alaska. The positions of the equatorward and of the poleward boundaries of the auroral oval are defined from each data source and are thereafter cross-calibrated to the JHU/APL automated DMSP boundaries described by Newell et al. (1996). The equatorward boundary used is the zeroenergy boundary of the electron precipitation (b1e boundary) defined by Newell et al. (1996), and the poleward boundary is the open/closed boundary (Sotirelis and Newell, 2000). Color coded is the differential energy flux of the precipitating electrons in units of $\log 10 \mathrm{eV} / \mathrm{cm}^{2} \mathrm{~s}$ str estimated from the Boundary-Oriented Precipitation Model described by Sotirelis and Newell (2000).

The blue line overlaid on the polar plot represents the approximate orbit of the Astrid-2 satellite during the time interval 23:25 to 23:55 UT. The location of the electric field peak observed by Astrid-2 at 23:34 UT is marked with a blue dot on the track of the satellite. Its position is seen to coincide well with the crossing of the equatorward boundary of the auroral oval at about 02:14 MLT. Moreover, the electric field data (Fig. 2, panels 1 and 2) do not show any significant fluctuations equatorward of the electric field peak, while on its poleward side the electric field varies more significantly as expected inside the auroral oval. We therefore conclude that the strong electric field peak measured at 23:34 UT is located at or very near to the equatorward edge of the auroral oval in the postmidnight sector. This electric field points mainly equatorward, has a maximum equatorward amplitude of about $115 \mathrm{mV} / \mathrm{m}$ and a full width at half maximum (FWHM) of $\sim 0.5^{\circ}$ CGLat. Hence, it corresponds to a rather thin region of rapid eastward ion $\operatorname{drift}(\sim 2700 \mathrm{~m} / \mathrm{s})$ located at the equatorward edge of the auroral oval. It can therefore be considered to be the opposite signature of that of a SAID, or in other words, it is the signature of an abnormal subauroral ion drift (ASAID), as termed by Voiculescu and Roth (2008).

About $3 \mathrm{~h}$ and 30 min prior to detection of the ASAID peak shown in Fig. 2, another ASAID electric field peak slightly stronger and with about the same FWHM was detected at approximately the same location. The electric field eastward and equatorward components are plotted in Fig. 3. These cases are possibly the signatures of the same ASAID event located at approximately the same positions, with a time interval of about $3 \mathrm{~h}$ and $30 \mathrm{~min}$ between their detections. Unfortunately, no data is available from the orbit with number 1649 (corresponding to the passage following the orbit shown in Fig. 3, and preceding the orbit shown in Fig. 2).

The selection of the data used on this statistical study was performed through visual inspection. The selected cases fulfill two criteria. The first criterion is that the electric field peak points mainly equatorward (i.e., the equatorward component is greater the eastward component). The second is that both the eastward and the equatorward components of the electric field are approximately constant equatorward of the electric field peak. The last criterion implies that the selected ASAID events are located at the equatorward edge of the auroral oval or equatorward of it. For the cases when the position of the auroral oval could be estimated using the OVATION tool, the ASAID event was confirmed to be 


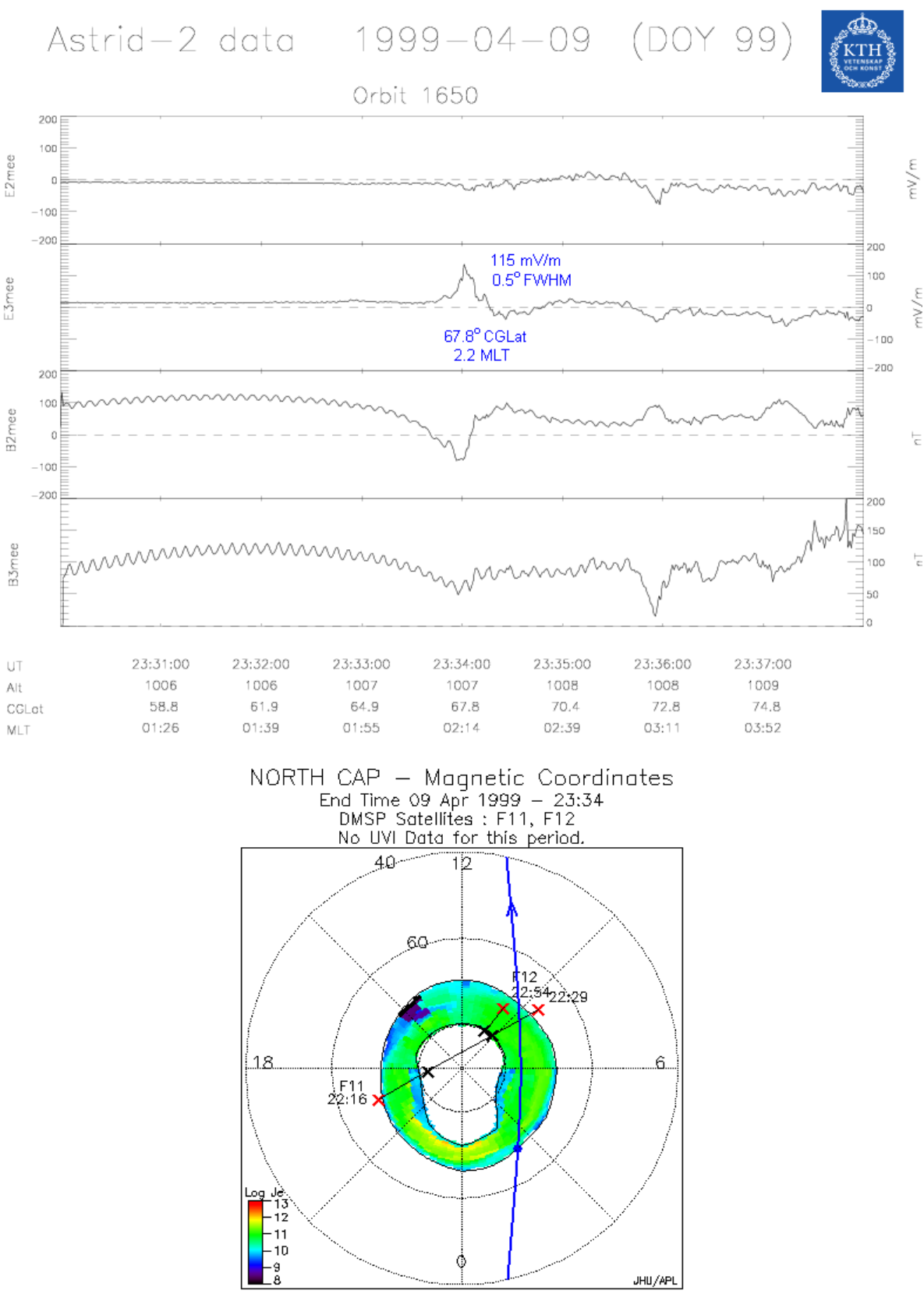

Fig. 2. The upper plot shows the eastward and the equatorward components of the electric and magnetic fields (panels $1,2,3$, and 4 , respectively), measured on 9 April 1999 between 23:30 and 23:38 UT. Universal time, altitude in kilometers, CGLat and MLT are given on the horizontal axis. In the lower part is shown a polar plot of the position of the auroral oval determined using the OVATION tool. The differential energy flux of the precipitating electrons in units of $\log 10 \mathrm{eV} / \mathrm{cm}^{2} \mathrm{~s}$ str is color coded. The orbit of the Astrid-2 satellite between 23:25 and 23:55 UT is overlaid with a blue line. The location of the ASAID peak measured at 23:34 UT is marked with a dot on the satellite track.

located very near to the equatorward edge of the modelled auroral oval, as for the case shown in Fig. 2.

From the inspection of about 2900 passages of the Astrid2 satellite over the Northern and the Southern auroral ovals, 23 ASAID events were selected. All of them are found right at the equatorward edge of the auroral oval. Their locations in CGLat and MLT coordinates are represented with squares in Fig. 4. The black segments indicate the amplitude and the direction of the electric field peak associated with each ASAID event.

The analysis of the auroral electrojet (AE) index for each ASAID event showed that the majority of the events occur 


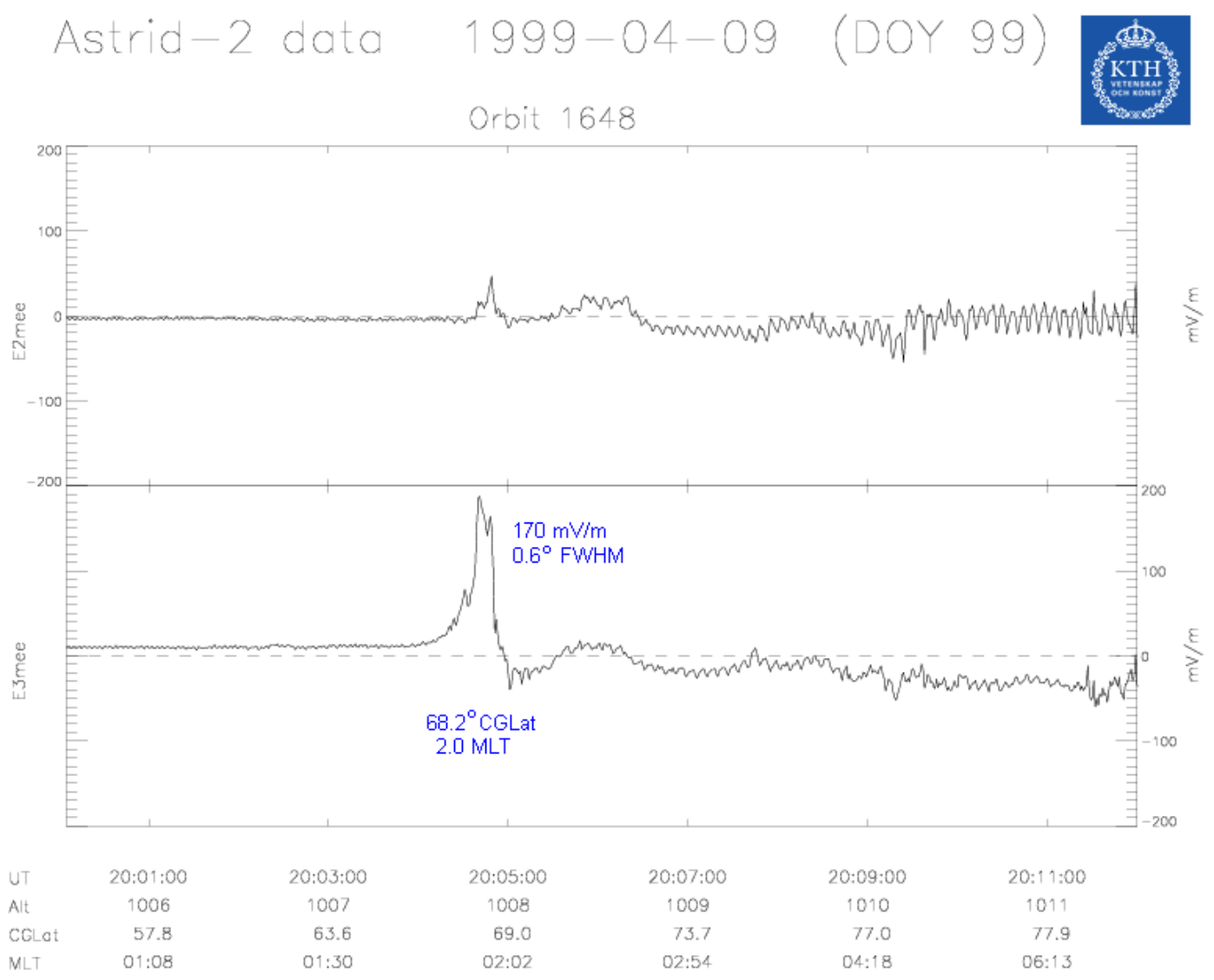

Fig. 3. Eastward and equatorward electric field components (panels 1 and 2, respectively) measured on 9 April 1999 between 20:00 and 20:12 UT.

during extended periods of low substorm activity. The duration in hours of the low activity period preceding the occurrence of each ASAID peak is designated by $\Delta t$ and is color coded in Fig. 4. Periods when the AE index is less than $200 \mathrm{nT}$ were considered as periods of low substorm activity. The instant when the AE index drops below $50 \mathrm{nT}$ after being equal or larger than $200 \mathrm{nT}$ was used as a proxy for the end of a substorm. $\Delta t$ is therefore the time interval between the occurrence of an ASAID event and the end of the last substorm preceding the ASAID occurrence. Only two events were detected during the development of a substorm. These are marked with blue squares. They occurred during the recovery phase of weak substorms (AE index peaks at $\sim 200 \mathrm{nT}$ in both cases). All other cases (green and red squares) occurred during periods of about 2 and up to $20 \mathrm{~h}$ of low substorm activity.

Figure 4 also shows that the ASAID events are located between $65^{\circ}$ and $70^{\circ}$ CGLat and between 23:00 and 03:00 MLT, and that the ASAID electric field points mainly equatorward for the majority of the cases. The geomagnetic $\mathrm{Kp}$ index is seen to be low (between 0.9 and 3) for all the events, also indicating low geomagnetic activity.
Figure 5 is a plot of the peak amplitude of the electric field equatorward component versus the corresponding FWHM for the selected events.

The majority of the ASAID events are seen to be $0.2^{\circ}$ to $1.2^{\circ}$ CGLat wide and to correspond to electric field peak amplitudes between $40 \mathrm{mV} / \mathrm{m}$ and $130 \mathrm{mV} / \mathrm{m}$. However, the peak amplitude reaches up to $185 \mathrm{mV} / \mathrm{m}$ in some few cases. A few events with FWHM between $2.0^{\circ}$ and $3.0^{\circ}$ CGLat are also observed. No clear correlation between the peak amplitude and the FWHM can be identified.

The analysis of the magnetic field data show that all the ASAID electric field peaks are associated with a small-scale current system composed of a region of downward FACs flowing in the poleward side of the ASAID structure and a region of upward FACs flowing in the equatorward side. The size of the current system is roughly the same as that of the corresponding ASAID structure. The density of the associated FACs varies between 0.5 and $2.0 \mu \mathrm{A} / \mathrm{m}^{2}$. The separation in degrees of CGLat between the locations of the ASAID electric field peak and the corresponding peak of the magnetic field eastward component (B2mee) was measured for each ASAID event and named $\Delta p o s$. Figure 6 is a bar plot showing the number of ASAID events for different intervals 


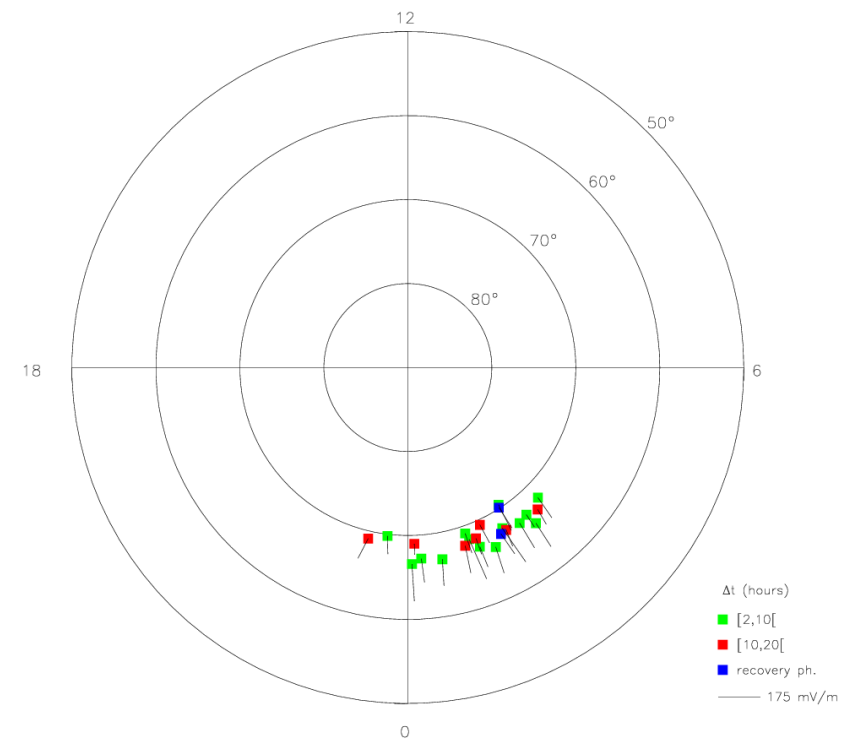

Fig. 4. Polar plot in CGLat and MLT coordinates of the location of the ASAID events (squares). The black segments indicate the amplitude and the orientation of the associated electric field peaks. The parameter $\Delta t$ is color coded.

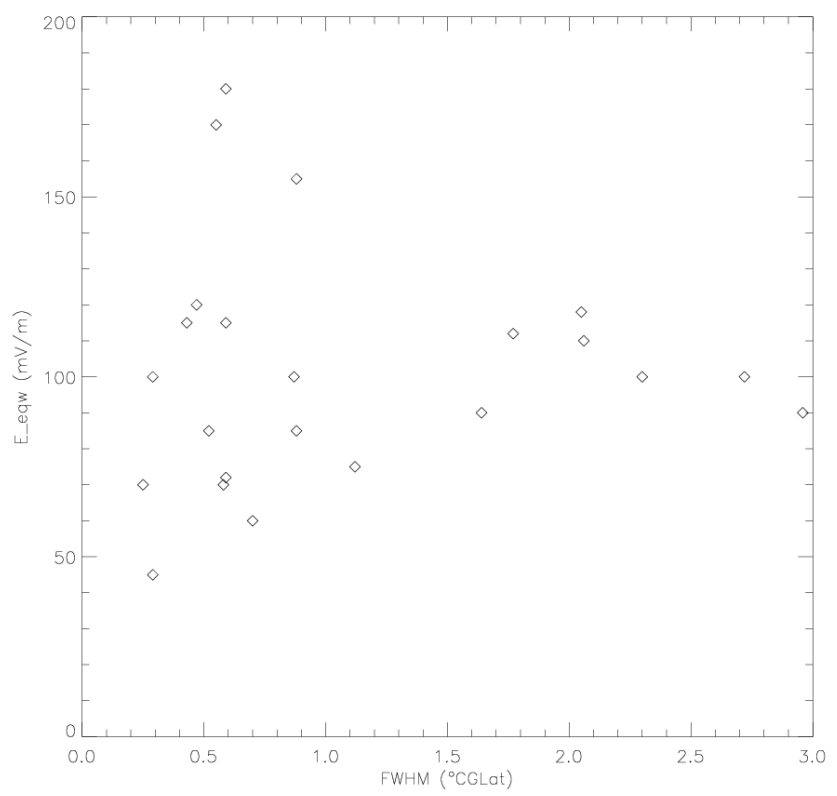

Fig. 5. Peak amplitude of the equatorward electric field component versus the corresponding FWHM for the selected ASAID events.

of $\Delta p o s$. Positive values of $\Delta p o s$ correspond to a displacement of the electric field peak toward the region of downward flowing FACs.

Figure 6 shows that for about half of the ASAID events the electric field peak is located very close to the corresponding magnetic field peak. Furthermore, the variations of the magnetic field follow rather well the variations of the elec-

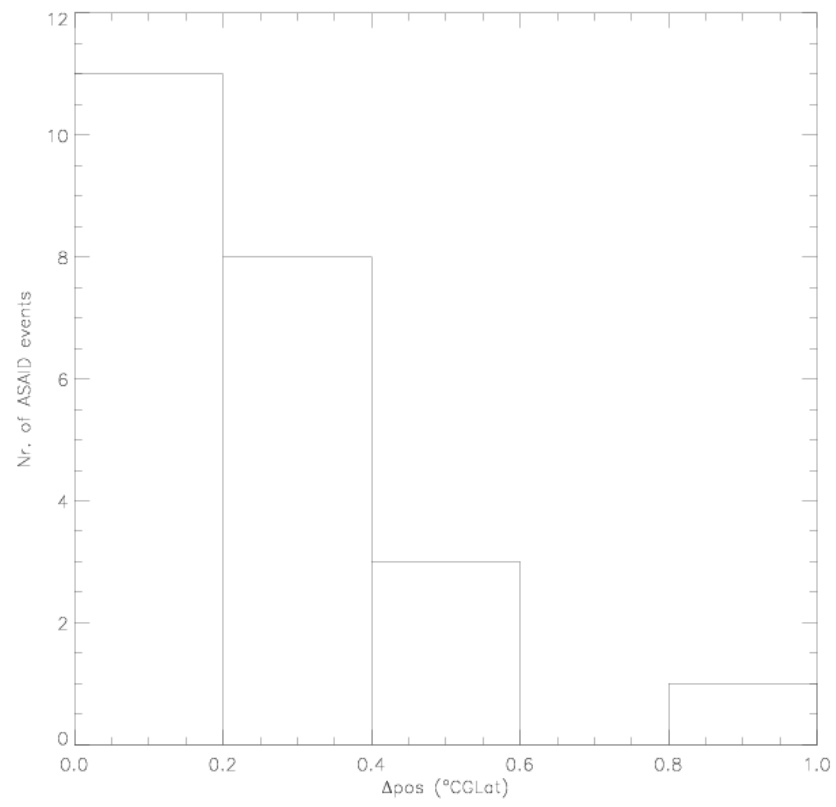

Fig. 6. Bar plot showing the number of ASAID events for different intervals of $\triangle$ pos. $\triangle$ pos represents the separation in degrees of CGLat between the peak locations of the electric and the magnetic fields. Positive values of $\Delta$ pos indicate that the electric field peak is displaced toward the region of downward flowing FACs.

tric field, suggesting a nearly constant conductivity in the ASAID region. For the other half of the cases the ASAID electric field peak is slightly displaced toward the region of downward flowing FACs. This small shift between the electric and the magnetic fields suggests a slight spatial variation on the ionospheric conductivity. However, one may conclude that no significant depletions of the ionospheric conductivity are seen associated with the ASAID events.

\section{Discussion}

An ASAID event is identified in this study as corresponding to an electric field directed mainly equatorward and located at the equatorward boundary of the auroral oval or equatorward of it. In addition, the results presented in this statistical study show that ASAID have the following properties:

- Correspond to electric field peak amplitudes between $45 \mathrm{mV} / \mathrm{m}$ and $185 \mathrm{mV} / \mathrm{m}$.

- Have typical latitudinal extensions between $0.2^{\circ}$ and $1.2^{\circ}$, in some cases up to $3.0^{\circ}$.

- Occur mainly during extended periods of low magnetic activity.

- Occur predominantly in the 23:00-03:00 MLT sector, between $65^{\circ}$ and $70^{\circ}$ CGLat.

- Are located at the equatorward edge of the auroral oval. 
- Can have life times at least up to $3.5 \mathrm{~h}$.

- Are associated with a downward/upward FAC region located in the poleward/equatorward side of the ASAID region, respectively. The density of the FACs varies between 0.5 and $2.0 \mu \mathrm{A} / \mathrm{m}^{2}$.

- Do not significantly modify the ionospheric conductivity.

The ASAID phenomenon clearly differs from the SAID in some properties, namely: the MLT location (SAID occur predominantly in the premidnight sector), the relation to substorm activity (SAID occur often during the recovery phase of a substorm), and the relation to modifications of the local ionospheric conductivity (SAID are commonly associated with a further depletion of the ionospheric conductivity). On the other hand, the SAID and the ASAID electric fields have peak amplitudes of the same order of magnitude, have similar latitudinal extensions, and are located at or close to the equatorward edge of the auroral oval.

The similarities between SAID and ASAID together with the premidnight/postmidnight asymmetry of their MLT location, suggests that these phenomena may be generated by the same mechanism. A discussion of different possible mechanisms that may lead to the formation of SAID and ASAID electric fields is conducted below.

First, we shall give a short description of the three main mechanisms that have been proposed to explain the generation of SAID electric fields.

- Southwood and Wolf (1978): The requirement of current closure through the strong conductivity gradient at the equatorward edge of the plasma sheet electron precipitation (equatorward edge of the diffuse aurora), combined with a strong low-latitude shielding of convection, produces enhanced midlatitude east-west flows equatorward of the auroral zone, whenever the inner edges of the ion plasma sheet and of the electron plasma sheet are close but not coincident.

This model is based on the assumption that the ionospheric mapping of the ion plasma sheet inner edge is located equatorward of the auroral conductivity discontinuity, to where the inner edge of the electron plasma sheet maps. Furthermore, it is considered that the ion plasma sheet totally shields the convection electric field from lower L-values. These conditions are restricted to the premidnight sector, where the plasma sheet positive ions penetrate deeper into the inner magnetosphere than the plasma sheet electrons.

- Anderson et al. (1993): The poleward electric field associated with SAID is generated as the result of the current closure of the region-2 downward FACs with the region-1 upward FACs in the dusk-premidnight sector, by means of ionospheric Pedersen currents. The region2 downward FACs expands to subauroral latitudes during substorms, and therefore the closing Pedersen currents flow through the low conductivity region of the midlatitude trough. Frictional heating of the neutrals due to the drifting ions contributes to the further reduction of the ionospheric plasma density, which leads to the strengthening of the SAID electric field.

- Keyser et al. (1998): Fine-scale structure generated by the strong temperature gradient across the interface between the cold plasmaspheric trough and hot plasma injected from the plasma sheet at substorm onset, leads to the formation of intense radial electric fields that map to the ionosphere as narrow SAID. The additional consideration of the azimuthal flow shear between the partially corotating plasma trough and the injected plasma, which drifts westward in the premidnight sector and eastward in the post-midnight sector, explains the higher occurrence probability of SAID in the premidnight sector: the electric field associated with the convecting plasma in the evening sector adds to the thermoelectric field, while it suppresses the thermoelectric field in the postmidnight sector.

Before discussing how these mechanisms may relate to the formation of ASAID electric fields, let us analyze the configuration of the inner magnetosphere during magnetic quiet times.

Under extended quiet time conditions the plasmapause is known to expand to larger distances from Earth as higher altitude flux tubes are slowly filled with plasma (Carpenter and Anderson, 1992). On the other hand, during magnetic active periods the magnetospheric convection strips off the outer layers of the plasmasphere resulting in a location of the plasmapause closer to Earth. O'Brien and Moldwin (2003) have shown that the plasmapause may be located at a distance of about 6 to 7 Earth radii from Earth (in the equatorial plane) during quiet times, with a bulge located before dawn in the postmidnight sector. The location of the bulge rotates through midnight toward the dusk and moves closer to Earth with increasing magnetic activity, reaching a minimum distance from Earth of about 2 Earth radii.

The position of the plasmapause influences the primary processes contributing to the loss and to the energization of the radiation belts and the ring current (Summers et al., 1998; O'Brien and Moldwin, 2003). Le et al. (2004) showed that the center position of the ring current also moves to larger distances from Earth with decreasing magnetic activity: it is located at about 5 Earth radii during storm-time periods and it extends to about 6 Earth radii far from the Earth during magnetic quiet times.

The level of magnetic activity also affects the location of the inner edges of the electron and the ion plasma sheets (Ejiri et al., 1980; Burke et al., 1998; Wang et al., 2008). They are also located farther from the Earth during quiet 
magnetic periods. Furthermore, they are expected to be located closer to each other during periods of extended low activity (Newell and Meng, 1987; Larsen et al., 2007).

Based on these results and on the mechanism proposed by Voiculescu and Roth (2008) for the generation of ASAID, one may draw a scenario where the plasmapause and the ring current outer edge are located very close to each other or even coincide, during extended quiet times. Moreover, the inner edges of the ion and the electron plasma sheets also coincide or are located very near to each other.

Assuming that the locations of the inner edges of the ion and the electron plasma sheets do not perfectly coincide but are instead separated by a small distance, the model presented by Southwood and Wolf (1978) predicts the formation of strong subauroral east-west flows in the premidnight sector, explaining the predominant occurrence of SAID in this region. It however does not explain the observations of ASAID reported in this study.

Let us instead consider the mechanism where the close locations of the electron and the ion plasma sheets inner edges generates a thin charge-separation layer between these boundaries. Since the inner edge of the ion plasma sheet is located closer to/farther from the Earth than the electron plasma sheet inner edge in the premidnight/postmidnight region of the equatorial plane, the generated charge-separation electric field is directed radially tailward/Earthward in the equatorial plane, respectively. This corresponds to a poleward/equatorward-directed electric field in the premidnight/postmidnight MLT region, respectively, when mapping down to the ionosphere.

This mechanism explains most of the ASAID properties described in the present study. It explains the observed collocation of the ASAID electric field peaks with the equatorward edge of the auroral oval, that is generally considered to be magnetically connected to the inner plasma sheet boundary; it supports the result that ASAID occurs mainly in the postminight sector; it is consistent with the fact that ASAID occurs mainly during extended quiet periods, and that it is located at larger geomagnetic latitudes $\left(65^{\circ}-70^{\circ}\right.$ CGLat $)$, as expected from the larger radial distance of the plasma sheet inner boundary during quiet times. The downward/upward field-aligned current system seen associated with ASAID is consistent with a short-circuiting through the subauroral ionosphere of the magnetospheric charge-separation electric field. Furthermore, the minimal size of the charge separation layer during extended quiet times, justifies the observed narrow widths of the ASAID events.

In a similar way, this mechanism also predicts the formation of narrow regions of SAID in the premidnight sector during extended quiet times. SAID is known to be substormrelated, occurring predominantly during the recovery phase of substorms. However, in a statistical study conducted by (Figueiredo et al., 2004), some SAID cases have also been observed during quiet magnetic times when the magnetic activity index $\mathrm{Kp}$ was less than 2, and/or after about to $2.5 \mathrm{~h}$ from substorm onset (Figueiredo et al., 2004). These cases appeared however to occur more seldom.

We do not believe that a mechanism similar to the one proposed by Anderson et al. (1993) for the formation of SAID, may also explain the formation of ASAID. It would require that the region- 2 upward FACs of the postmidnight sector expands toward lower latitudes, covering the location of the midlatitude trough. Although the midlatitude trough is known to be located between 18:00 and 06:00 MLT and to move to higher latitudes during quiet magnetic times (Rodger et al., 1992), the extension of the region-2 upward FACs of the postmidnight sector over the region of the midlatitude trough, during periods of low substorm activity, is rather unlikely to occur. Furthermore, the results presented in this study shows that ASAID do not contribute to the reduction of the ionospheric conductivity, as opposite to the predictions by Anderson et al. (1993) when explaining the formation and development of SAID.

According to the model proposed by Keyser et al. (1998), the interaction between the cold plasmatrough and hot plasma injected from the plasma sheet at substorm onset, generates SAID electric fields. We propose some modifications to this model in order to explain the formation of ASAID electric fields.

Let us consider the hypothetical scenario drawn for quiet magnetic times, where the outer edge of the ring current coincides with the plasmapause or is located slightly farther from Earth than the plasmapause. Moreover, the ion and the electron plasma sheet inner edges are assumed to coincide and to be located very near to the ring current outer edge, implying a thin plasmaspheric trough, and therefore a near collocation of the ionospheric mapping of the plasma sheet inner edge (equatorward edge of the auroral oval) with the ionospheric projection of the ring current outer edge.

Under these conditions, finite Larmor radius effects at the interface between the hot ring current and the colder plasmaspheric trough may generate a radial electric field pointing inward at the ring current outer edge. The larger Larmor radius of the ring current ions as compared to the Larmor radius of the trough ions creates an excess of positive charges on the outer side of the ring current outer edge, generating a radial electric field pointing inward at this boundary, that maps to the ionosphere as an equatorwarddirected electric field. But how to explain the predominance of ASAID occurrence in the postmidnight sector based on this mechanism? A possible answer is the premidnight/postmidnight asymmetry of the ionospheric convection electric field. The westward/eastward convection of the ionospheric plasma in the premidnight/postmidnight sector is associated with a poleward/equatorward-directed electric field that cancels/adds to the mapped charge-separation electric field at the equatorward edge of the auroral oval.

This mechanism explains our observations of narrow ASAID events located in the vicinity of the equatorward edge of the auroral oval. Moreover, it predicts the occurrence 
of ASAID in the postmidnight sector during quiet magnetic times.

If the convection electric field does not fully cancel the mapped charge-separation electric field in the premidnight sector, ASAID electric fields are also expected to occur in this region. In fact, the ASAID events reported by Voiculescu and Roth (2008) were detected during periods of weak substorm activity, and were located at 20:00-22:00 MLT very close to the equatorward edge of the dusk convection cell. A mechanism similar to the one presented above was indeed presented by Voiculescu and Roth (2008) to explain their observations. The authors also reported on the observation of an ASAID event reversing into a SAID after a time interval of 9-12 $\mathrm{h}$. The ASAID/SAID reversing was suggested to occur when injected hot electrons come close enough to the positive sheet of the charge-separation layer associated with the ASAID, generating an electric field that points radially outward and that maps to the ionosphere as a poleward-directed electric field.

As reported by Ebihara et al. (2008), ASAID events have also been observed in the predusk sector associated with an intense magnetic storm. They occurred after a sudden northward turning of the interplanetary magnetic field (IMF). The authors justified the formation of these events based on the overshielding effect resultant from the sudden northward turning of the IMF. We have analyzed IMF data for the events reported on this study, and have not found any such case.

\section{Conclusions and future work}

We present results from a statistical study on ASAID occurrence. ASAID are narrow regions of rapid eastward plasma flow observed in the subauroral region. They seem to occur more rarely than SAID justifying why only recently the first observations of ASAID have been reported, while SAID have been the subject of investigation during more than 30 years. Our results show that ASAID occur predominantly during extended periods of low substorm activity, in the postmidnight sector (23:00-03:00 MLT), and in the vicinity of the equatorward edge of the auroral oval. They are associated with a downward/upward field-aligned current system located in the poleward/equatorward edges of the ASAID region. No significant depletion of the ionospheric conductivity is seen in the ASAID region. A life time at least up to $3.5 \mathrm{~h}$ was measured for one case.

Since our observations are only from the ionospheric end of the ASAID flux tube, we are not able to determine exactly the magnetospheric generation mechanism/mechanisms responsible for the ASAID formation. However, we believe that the close locations of the inner edges of the ion and the electron plasma sheets, as well as of the plasmapause and the ring current outer edge, that is most likely to occur during extended quiet periods, play an important role in the ASAID formation.
The further understanding of the dynamics of the inner magnetosphere and the coupling with the ionospheric subauroral region will definitely benefit from conjugate observations between low altitude-orbiting satellites and crossings of the inner-magnetospheric boundaries.

Acknowledgements. The AE index used in this study was obtained from the World Data Center for Geomagnetism operated by the Data Analysis Center for Geomagnetism and Space Magnetism Graduate School of Science, Kyoto University. The data is available through the website http://swdcwww.kugi.kyoto-u.ac.jp/index.html. The OVATION plots used in this study were obtained through the website http://sd-www.jhuapl.edu/Aurora/ maintained by the Johns Hopkins University Applied Physics Laboratory.

Topical Editor M. Pinnock thanks Y. Ebihara and M. Voiculescu for their help in evaluating this paper.

\section{References}

Anderson, P. C., Hanson, W. B., Heelis, R. A., Craven, J. D., Baker, N. D., and Frank, L. A.: A proposed production model of rapid subauroal ion drifts and their relation to substorm evolution, J. Geophys. Res., 98, 6069-6078, 1993.

Blomberg, L. G., Marklund, G. T., Lindqvist, P.-A., Primdahl, F., Brauer, P., Bylander, L., Cumnock, J. A., Eriksson, S., Ivchenko, N., Karlsson, T., Kullen, A., Merayo, J. M. G., Pedersen, E. B., and Petersen, J. R.: EMMA - the Electric and Magnetic Monitor of the Aurora on Astrid-2, Ann. Geophys., 22, 115-123, 2004, http://www.ann-geophys.net/22/115/2004/.

Burke, W. J., Maynard, N. C., Hagan, M. P., Wolf, R. A., Wilson, G. R., Gentile, L. C., Gussenhoven, M. S., Huang, C. Y., Garner, T. W., and Rich, F. J.: Electrodynamics of the inner magnetosphere observed in the dusk sector by CRRES and DMSP during the magnetic storm of June 4-6, 1991, J. Geophys. Res., 103, 29399-29418, 1998.

Carpenter, D. L. and Anderson, R. R.: An ISEE/whistler model of equatorial electron density in the magnetosphere, J. Geophys. Res., 97, 1097-1108, 1992.

Ebihara, Y., Nishitani, N., Kikuchi, T., Ogawa, T., Hosokawa, K., and Fok, M.-C.: Two-dimensional observations of overshielding during a magnetic storm by the Super Dual Auroral Radar Network (SuperDARN) Hokkaido radar, J. Geophys. Res., 113, A01213, doi:10.1029/2007JA012641, 2008.

Ejiri, M., Hoffman, R. A., and Smith, P. H.: Energetic particle penetrations into the inner magnetosphere, J. Geophys. Res., 85, 653$663,1980$.

Figueiredo, S., Karlsson, T., and Marklund, G. T.: Investigation of subauroral ion drifts and related field-aligned currents and ionospheric Pedersen conductivity distribution, Ann. Geophys., 22, 923-934, 2004, http://www.ann-geophys.net/22/923/2004/.

Galperin, Y. I., Ponomarev, V. N., and Zosimova, A. G.: Plasma convection in the polar ionosphere, Ann. Geophys., 30, 1-7, 1974.

Karlsson, T., Marklund, G. T., Blomberg, L. G., and Mälkki, A.: Subauroral electric fields observed by the Freja satellite: A statistical study, J. Geophys. Res., 103, 4327-4341, 1998. 
Keyser, J. D., Roth, M., and Lemaire, J.: The magnetospheric driver of subauroral ion drifts, Geophys. Res. Lett., 25, 1625-1628, 1998.

Larsen, B. A., Klumpar, D. M., and Gurgiolo, C.: Cross-tail electric field magnitude derived from plasmaspheric Alfvén layer motions, AGU, Fall Meeting, abstract \#SM31B-02, 2007.

Le, G., Russell, C. T., and Takahashi, K.: Morphology of the ring current derived from magnetic field observations, Ann. Geophys., 22, 1267-1295, 2004,

http://www.ann-geophys.net/22/1267/2004/.

Marklund, G. T., Blomberg, L. G., and Persson, S.: Astrid-2, an advanced microsatellite for auroral research, Ann. Geophys., 19, 589-592, 2001, http://www.ann-geophys.net/19/589/2001/.

Newell, P. T. and Meng, C. I.: Low altitude observations of dispersionless substorm injection fronts, J. Geophys. Res., 92, 1006310072, 1987.

Newell, P. T., Feldstein, Y. I., Galperin, Y. I., and Meng, C. I.: The morphology of nightside precipitation, J. Geophys. Res., 101, 10737-10748, 1996.

O'Brien, T. P. and Moldwin, M. B.: Empirical plasmapause models from magnetic indices, Geophys. Res. Lett., 30, 1152, doi:10,1029/2002GL016007, 2003.

Puhl-Quinn, P. A., Matsui, H., Mishin, E., Mouikis, C., Kistler, L., Khotyaintsev, Y., Décréau, P. M. E., and Lucek, E.: Cluster and DMSP observations of SAID electric fields, J. Geophys. Res., 112, A05219, doi:10.1029/2006JA012065, 2007.
Rodger, A., Moffett, R. J., and Quegan, S.: The role of ion drift in the formation of ionisation troughs in the mid- and high-latitude ionosphere-a review, J. Atmos. Terr. Phys., 54, 1-30, 1992.

Smiddy, M., Kelley, M. C., Burke, W., Rich, F., Sagalyn, R., Schuman, B., Hays, R., and Lai, S.: Intense poleward-directed electric fields near the ionospheric projection of the plasmapause, Geophys. Res. Lett., 4, 543-546, 1977.

Sotirelis, T. and Newell, P. T.: Boundary-oriented electron precipitation model, J. Geophys. Res., 105, 18655-18673, 2000.

Southwood, D. J. and Wolf, R. A.: An assessment of the role of precipitation in magnetospheric convection, J. Geophys. Res., 83, 5227-5232, 1978.

Spiro, R. W., Hanson, W. B., Sterling, D. L., and Hoffman, R. A.: Midlatitude trough characteristics as observed by Atmosphere Explorer, Trans. Am. Geophys. Union, 55, 1159, 1974.

Summers, D., Thorne, R. M., and Xiao, F.: Relativistic theory of wave-particle resonant diffusion with application to electron acceleration in the magnetosphere, J. Geophys. Res., 103, 2048720500, 1998.

Voiculescu, M. and Roth, M.: Eastward sub-auroral ion drifts or ASAID, Ann. Geophys., 26, 1955-1963, 2008, http://www.ann-geophys.net/26/1955/2008/.

Wang, C.-P., Lyons, L. R., Angelopoulos, V., Larson, D., McFadden, J. P., Frey, S., Auster, H.-U., and Magnes, W.: THEMIS observations of penetration of the plasma sheet into the ring current region during a magnetic storm, Geophys. Res. Lett., 35, L17S14, doi:10.1029/2008GL033375, 2008. 